\title{
Concurrent crack and powder cocaine users from Sao Paulo: Do they represent a different group?
}

\author{
Camila Guindalini ${ }^{1,2}$, Homero Vallada1 ${ }^{1}$, Gerome Breen*2 and \\ Ronaldo Laranjeira 3
}

Address: ${ }^{1}$ Department of Psychiatry, University of São Paulo Medical School, Brazil, ${ }^{2}$ MRC Social Genetic and Developmental Psychiatry Research Centre, Institute of Psychiatry, King's College London, UK and ${ }^{3}$ UNIAD (Unit of Drug and Alcohol Research), Department of Psychiatry, Federal University of São Paulo, Brazil

Email: Camila Guindalini - c.guindalini@iop.kcl.ac.uk; Homero Vallada - hvallada@usp.br; Gerome Breen* - g.breen@iop.kcl.ac.uk; Ronaldo Laranjeira - laranjeira@psiquiatria.epm.br

* Corresponding author

Published: 20 January 2006

BMC Public Health 2006, 6:10 doi:10.1 I86/147I-2458-6-10
Received: 27 April 2005

Accepted: 20 January 2006

This article is available from: http://www.biomedcentral.com/I47I-2458/6/10

(C) 2006 Guindalini et al; licensee BioMed Central Ltd.

This is an Open Access article distributed under the terms of the Creative Commons Attribution License (http://creativecommons.org/licenses/by/2.0), which permits unrestricted use, distribution, and reproduction in any medium, provided the original work is properly cited.

\begin{abstract}
Background: Cocaine abuse is a serious and socially damaging illegal drug problem. Different routes of administration are associated with a specific progression of use, different degrees of abuse liability, propensity for dependence and treatment response. There have been relatively few studies comparing different cocaine users groups and no studies into the characterization of the group of individuals reporting concurrent use of powder cocaine and crack cocaine.
\end{abstract}

Methods: Six hundred and ninety-nine cocaine users were assessed during the period August 1997 to October 1998 in one outpatient and six inpatient clinics located in the São Paulo, Brazil. Patients were interviewed using a structured questionnaire schedule in Portuguese, designed specifically for the Brazilian population. The statistical analyses were performed using either ANOVA or a chisquared test and focusing on their preferred form of use/route of administration and other variables.

Results: For $83 \%$ of the variables tested in this study, the Dual Users subgroup (using both powder and crack cocaine) demonstrated statistical differences from the single drug user subgroups. Those differences include the initiation of cocaine, the abuse of other illicit drugs, and rates of criminal history.

Conclusion: These data suggest cocaine-dependent individuals who report use of both powder and crack cocaine are an at least partially, distinct subgroup. However, further studies will be necessary to confirm this and to determine if they also show a different treatment response.

\section{Background}

Cocaine abuse is one of the most serious and socially damaging illegal drug problems. The 2003 US National Survey on Drug Use and Health [1] found that $14.7 \%$ of the population of the United States aged 12 and older had tried cocaine at least once in their lifetimes. In Europe, the highest rate with a lifetime prevalence of $5.2 \%$ was reported for the United Kingdom [2]. In Brazil it is estimated that $10 \%$ of those aged $18-28$ years in Sao Paulo have used cocaine at least once [3]. However, it remains 
unclear how many current users there are, or how many are prone to dependence.

The phases of dependence can be defined by different clinical characteristics in relation to dose, administration route, and length and pattern of cocaine use. There are positive correlations between drug abuse liability, intensity of intoxication and reported euphoria, with bioavailability of the substance in the central nervous system, and speed at which the maximum concentration in the brain is reached after ingestion. Consequently, route of administration can have important implications in the development of addictive behaviour(s). Crack cocaine, in comparison to cocaine hydrochloride, or powder cocaine, provides an immediate euphoric effect and is associated with high dependence liability and distinct treatment outcomes [4-6]. Intriguingly, studies investigating changes in routes of administration and patterns of cocaine use in Brazil demonstrated an important increase in the number of people reporting crack cocaine use in the last decade [712]. Although some of these studies identified three distinct groups of users $[9,10,12]: 1)$ individuals who were only snorting cocaine, 2) individuals who were only smoking cocaine and 3) a large group of individuals who were using both routes of administration concurrently, characterization and comparisons have tended to consider two groups only: crack and powder cocaine users, where patients reporting more than one route were counted per route $[9,12]$.

The present study describes the socio-demographic characteristics and drug abuse history among cocaine users from Sao Paulo, aiming to better characterize the different subgroups of users divided by their preferred form of use and route of administration, focusing on the analysis of dual users separately from the ones who use crack or powder cocaine only.

\section{Methods}

\section{Sampling}

Although this sample is essentially a convenience sample, it was intentionally selected from a wide range of services with diverse characteristics to avoid an ascertainment bias [13]. The study group consisted of drug users who were in detoxification, abstinence or counselling treatment from August 1997 to October 1998 in six inpatients and one outpatient clinic located in the metropolitan region of São Paulo City. The catchment area comprises the population of Sao Paulo and 39 smaller surrounding cities, the largest Brazilian (and South American) urban area. These drug treatment centres accounted for an estimated $75 \%$ of all hospitalizations related to drug abuse or illegal drug dependence carried out during the study period.

\section{Subjects}

Inclusion criteria were: age 18 years and older, a history of primary or only cocaine abuse and under treatment at the selected centres. Individuals with history of exclusive alcohol dependence and mental disability were excluded. A total of 699 patients were interviewed and gave written informed consent. Subjects also gave a small sample of blood for genetic studies and HIV testing. This project was approved by the Ethical Committee of the Federal University of São Paulo and other relevant local ethics committees. HIV incidence investigation and a subgroup profile description were published previously $[12,15]$.

\section{Measurements}

A structure interview schedule in Portuguese had been designed specifically for the Brazilian population [14] and was comprehensively piloted previously. The questionnaire covers socio-demographic characteristics, sexual behaviours, and drug use profile. Responses to questions were dichotomous, multiple-choice or numeric in format. As the majority of the questions had a screening approach, the time taken to complete the interview was approximately 20 minutes (for details, see Ferreira-Filho et al, 2003). Interviews were conducted by three researchers, either experienced psychiatrists or psychologists who had been trained to use the questionnaire. All subjects satisfied an ICD10 diagnosis [16] of cocaine dependence (ICD 10 code F14.2).

\section{Statistical analyses}

A datafile was created for use with SPSS statistical software, v.12.0. The statistical significance of differences between the groups was established using either an ANOVA test for comparisons of means or a $\chi^{2}$ test for comparison of categorical data. In addition the Kolmogorov-Smirnov Test was used for analyses of continuous, non-parametric data.

\section{Results}

The study sample comprised 699 Cocaine Users. The predominant preferred forms of administration were powder cocaine for $22.6 \%$ of the participants and crack cocaine for $7.9 \%$ while the majority, $69.5 \%$, reported using both routes concurrently. In order to conduct a comparative analysis the sample was divided as follows: 1) Powder Cocaine Users, individuals who used cocaine or powder cocaine 2) Crack Cocaine Users, individuals who used the freebase processed cocaine hydrochloride commonly known as "crack" and 3) Dual users, individuals who reported using both forms of cocaine.

\section{Socio demographic characteristics}

A summary of socio demographic data is presented in Table 1 . Ninety-five per cent of the sample $(n=668)$ were male, and this proportion was consistent among the three 
Table I: Comparison of socio-demographic characteristics among Powder Cocaine Users, Crack Cocaine Users and Dual Users groups.

\begin{tabular}{|c|c|c|c|c|c|c|c|c|}
\hline & \multicolumn{2}{|c|}{ Powder Cocaine Users } & \multicolumn{2}{|c|}{ Crack Cocaine Users } & \multicolumn{2}{|c|}{ Dual Users } & Total & pvalue \\
\hline \multirow[t]{2}{*}{ Age } & \multicolumn{2}{|c|}{28.1} & \multicolumn{2}{|c|}{26.8} & \multicolumn{2}{|c|}{26.2} & 26.7 & $p=0.01$ \\
\hline & \multicolumn{2}{|c|}{$\mathrm{SD}=7.7$} & \multicolumn{2}{|c|}{$S D=7.3$} & \multicolumn{2}{|c|}{$S D=6.8$} & 7.2 & \\
\hline \multicolumn{9}{|l|}{ Ethnicity } \\
\hline Caucasian & 125 & $80 \%$ & 34 & $63 \%$ & 339 & $70 \%$ & 498 & $p=0.01$ \\
\hline African & 31 & $20 \%$ & 20 & $37 \%$ & 143 & $30 \%$ & 194 & \\
\hline \multicolumn{9}{|l|}{ Sex } \\
\hline Male & 149 & $94 \%$ & 54 & $98 \%$ & 465 & $96 \%$ & 668 & $p>0.05$ \\
\hline Female & 9 & $6 \%$ & 1 & $2 \%$ & 21 & $4 \%$ & 31 & \\
\hline \multicolumn{9}{|l|}{ Education } \\
\hline primary school or less & 92 & $62 \%$ & 47 & $87 \%$ & 347 & $73 \%$ & 486 & $P=0.001$ \\
\hline secondary school or more & 57 & $38 \%$ & 7 & $13 \%$ & 127 & $27 \%$ & 191 & \\
\hline \multicolumn{9}{|l|}{ Marriage Status } \\
\hline single & 96 & $61 \%$ & 34 & $62 \%$ & 289 & $60 \%$ & 419 & $p>0.05$ \\
\hline married/cohabiting & 37 & $23 \%$ & 15 & $27 \%$ & 128 & $27 \%$ & 180 & \\
\hline divorced/widowed & 25 & $16 \%$ & 6 & $11 \%$ & 63 & $13 \%$ & 94 & \\
\hline
\end{tabular}

cocaine groups. The same consistency between groups was found when marriage status was analyzed: $60.4 \%$ were single, $26 \%$ were married or co-habiting and $13.6 \%$ were divorced, separated or widowed at the time of the interview. However, when age $\left(\mathrm{F}=4.3 ; \mathrm{df}_{\mathrm{b}}=2 ; \mathrm{df}_{\mathrm{w}}=696 ; \mathrm{p}=\right.$ $0.01)$, ethnic background $\left(\chi^{2}=7.9 ; \mathrm{df}=2 ; \mathrm{p}=0.01\right)$ and level of education $\left(\chi^{2}=14.1, \mathrm{df}=2, \mathrm{p}=0.001\right)$ were evaluated, statistic differences among groups could be identified.

Dual Users tended to be younger $(26.2 ; \mathrm{SD}=6.8)$ and have a higher percentage $(30 \%)$ of individuals with selfreported African ancestry than Powder Cocaine Users (28.1 years; $\mathrm{SD}=7.7$ and $20 \%$, respectively $) ;\left(\mathrm{F}=8.6, \mathrm{df}_{\mathrm{b}}=1\right.$; $\mathrm{df}_{\mathrm{w}}=642, \mathrm{p}=0.003$ and $\chi^{2}=5.7, \mathrm{df}=1, \mathrm{p}=0.017$, respectively), but did not statistically differ from Crack Cocaine
Users (26.8 years; $\mathrm{SD}=7.3$ and $37 \%$, respectively), $(\mathrm{F}=$ $0.4, \mathrm{df}_{\mathrm{b}}=1 ; \mathrm{df}_{\mathrm{w}}=539, \mathrm{p}>0.05$ and $\chi^{2}=1.2, \mathrm{df}=1, \mathrm{p}>$ 0.05 , respectively). Education attainment differed in the Dual Users, with $27 \%$ of the individuals having attended the secondary school/university (ages 15 and over), versus $38 \%$ in Powder Cocaine Users $\left(\chi^{2}=7.1, \mathrm{df}=1, \mathrm{p}=0.007\right)$ and was higher when compared with $13 \%$ in the Crack Cocaine Users $\left(\chi^{2}=4.9, \mathrm{df}=1, \mathrm{p}=0.02\right)$.

\section{Licit drug Use}

Eighty-four percent $(n=588)$ of the patients were smokers (Table 2). The percentage of smoking individuals was $88 \%$ in the Dual Users versus $74 \%$ in Powder Cocaine Users $\left(\chi^{2}=16.6, \mathrm{df}=1, \mathrm{p}<0.0001\right)$ and $85 \%$ in Crack Cocaine Users $\left(\chi^{2}=0.2, \mathrm{df}=1, \mathrm{p}>0.05\right)$. Regarding alcohol consumption, Dual Users reported to drink more alcohol per

Table 2: Comparison of history of legal and illegal drugs in the Powder Cocaine Users, Crack Cocaine Users and Dual Users groups and in the total sample.

\begin{tabular}{|c|c|c|c|c|c|c|c|c|}
\hline & \multicolumn{2}{|c|}{ Powder Cocaine Users } & \multicolumn{2}{|c|}{ Crack Cocaine Users } & \multicolumn{2}{|c|}{ Dual Users } & \multirow[t]{2}{*}{ Total } & \multirow[t]{2}{*}{ pvalue } \\
\hline \multicolumn{7}{|l|}{ Alcohol } & & \\
\hline $\begin{array}{r}<50 \text { units/ } \\
\text { week }\end{array}$ & 92 & $58 \%$ & 40 & $73 \%$ & 299 & $63 \%$ & 431 & $p>0.05$ \\
\hline $\begin{array}{r}>50 \text { units/ } \\
\text { week }\end{array}$ & 66 & $42 \%$ & 15 & $27 \%$ & 175 & $37 \%$ & 256 & \\
\hline \multicolumn{9}{|l|}{ Smoking } \\
\hline yes & 117 & $74 \%$ & 46 & $85 \%$ & 425 & $88 \%$ & 588 & $p>0.001$ \\
\hline no & $4 I$ & $26 \%$ & 8 & $15 \%$ & 60 & $12 \%$ & 109 & \\
\hline \multicolumn{9}{|l|}{ Cannabis } \\
\hline never used & 11 & $7 \%$ & 6 & $11 \%$ & 8 & $2 \%$ & 25 & $p>0.0001$ \\
\hline ever used & 147 & $93 \%$ & 49 & $89 \%$ & 469 & $98 \%$ & 665 & \\
\hline \multicolumn{9}{|l|}{ Solvents } \\
\hline never used & 70 & $44 \%$ & 29 & $53 \%$ & 118 & $24 \%$ & 217 & $p>0.0001$ \\
\hline ever used & 88 & $56 \%$ & 26 & $47 \%$ & 367 & $76 \%$ & 481 & \\
\hline \multicolumn{9}{|l|}{ Heroin } \\
\hline never used & 153 & $97 \%$ & 54 & $98 \%$ & 459 & $94 \%$ & 666 & $p>0.05$ \\
\hline ever used & 5 & $3 \%$ & 1 & $2 \%$ & 27 & $6 \%$ & 33 & \\
\hline
\end{tabular}




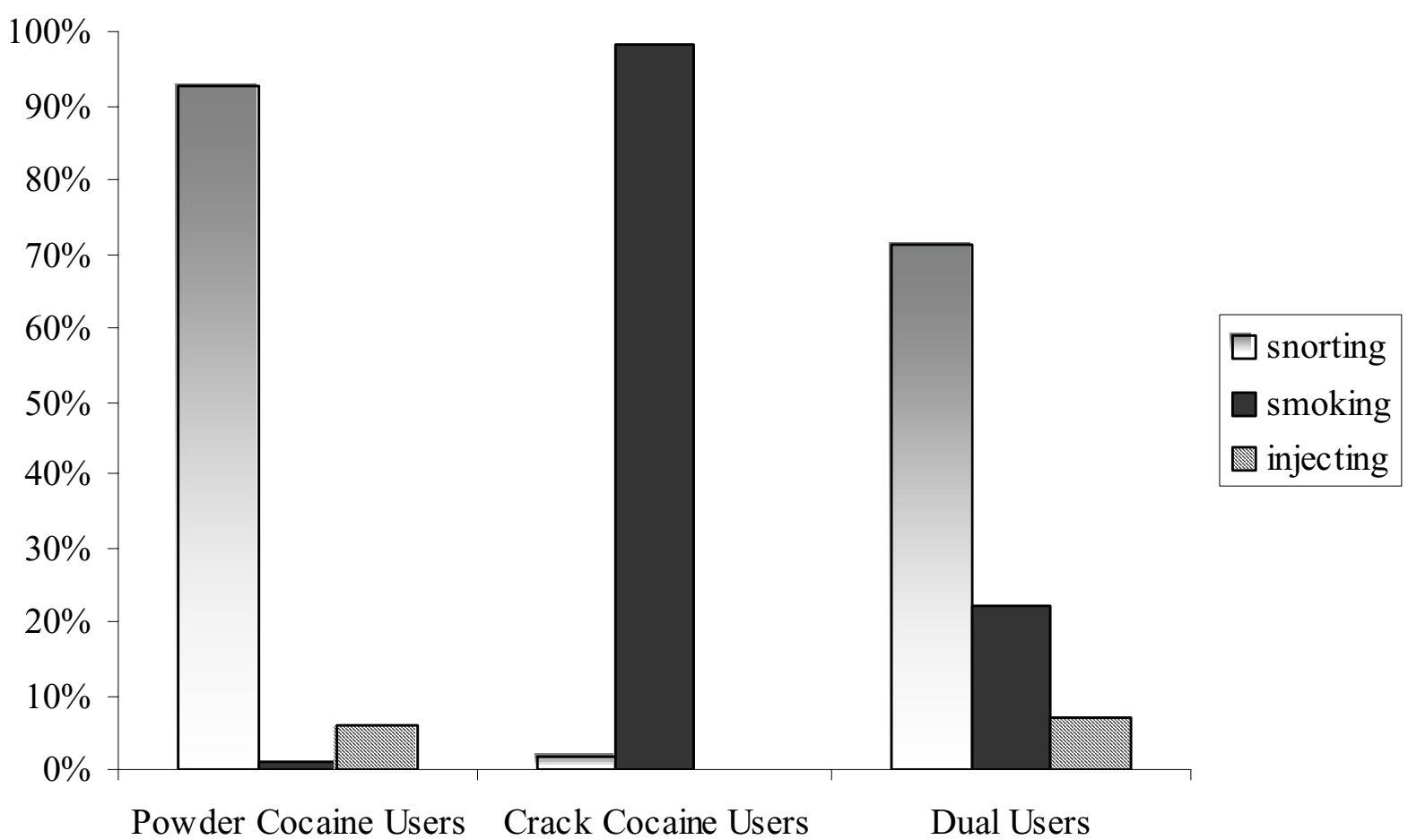

Figure I

The first route of administration in the Powder Cocaine Users, Crack Cocaine Users and Dual Users groups.

week than Crack Cocaine Users ( $\mathrm{ks}=1.6, \mathrm{p}=0.01$ ) Moreover $37 \%$ of the Dual Users reported consuming more than 50 units of alcohol per week, compared to $27 \%$ of the Crack Cocaine Users $\left(\chi^{2}=1.9, \mathrm{df}=1, \mathrm{p}>0.05\right)$ and $42 \%$ of the Powder Cocaine Users $\left(\chi^{2}=3.6, \mathrm{df}=1, \mathrm{p}=0.05\right)$.

\section{Illicit drug use}

When history of other illegal drugs was evaluated in the three groups, differences were found for cannabis $\left(\chi^{2}=\right.$ 18.6, $\mathrm{df}=2, \mathrm{p}<0.0001)$ and solvents $\left(\chi^{2}=35.2, \mathrm{df}=2, \mathrm{p}\right.$ $<0.0001)$ but not for heroin use $\left(\chi^{2}=2.6, \mathrm{df}=2, \mathrm{p}>0.05\right.$, see Table 2). The proportion of individuals that had ever used cannabis was higher in the Dual Users group when compared to both Powder Cocaine Users group $\left(\chi^{2}=11.4\right.$, $\mathrm{df}=1, \mathrm{p}=0.001)$ and Crack Cocaine Users $\left(\chi^{2}=16.4, \mathrm{df}=\right.$ $1, \mathrm{p}<0.001)$. Similar figures were observed for the use of solvents, with a increased number of individuals in the Dual Users group reporting to have ever used this substance in their life, compared to the Powder Cocaine Users and Crack Cocaine Users groups $\left(\chi^{2}=22.9, \mathrm{df}=1, \mathrm{p}<\right.$ 0.0001 and $\chi^{2}=20.1, \mathrm{df}=1, \mathrm{p}<0.0001$, respectively).

The use of both solvents and heroin in the last month prior to admission was low overall and did not differ among groups. The highest rates were 1.8\% for the use of solvents by the Crack Cocaine Users group and $0.8 \%$ for use of heroin in the Dual Users group. While the reported use of cannabis in the last month was high in all groups, it was particularly raised in the Dual Users (63\%) as compared to Powder Cocaine Users $\left(43 \%, \chi^{2}=19.2, \mathrm{df}=1, \mathrm{p}<\right.$ $0.001)$ and Crack Cocaine Users $\left(45 \%, \chi^{2}=6.3, \mathrm{df}=1, \mathrm{p}=\right.$ $0.01)$.

\section{Initiation into cocaine use}

The most common first routes of cocaine administration were snorting $(\mathrm{n}=571)$, then smoking $(\mathrm{n}=184)$ and injecting $(\mathrm{n}=50)$ - counting per route for individuals who reported two or more concomitant first routes. Separating the groups, snorting was the first route of choice for $93 \%$ of the Powder Cocaine Users and for $71 \%$ of the Dual Users. However, in the Crack Cocaine Users group, the first chosen route was smoking in $92 \%$ of the individuals (Figure 1), followed by snorting cocaine in only $8 \%$ of the individuals. The mean age of initiation of cocaine use was significantly different among the groups. Dual Users tend to start using cocaine earlier $(18.3$ years, $S D=5.4)$ than the Powder Cocaine Users (20.7 years, $\mathrm{SD}=7.4)(\mathrm{F}=18.1$, $\left.\mathrm{df}_{\mathrm{b}}=1 ; \mathrm{df}_{\mathrm{w}}=641, \mathrm{p}<0.0001\right)$ and the Crack Cocaine Users. 
(22.7 years, $\mathrm{SD}=8.1)\left(\mathrm{F}=28.4, \mathrm{df}_{\mathrm{b}}=1 ; \mathrm{df}_{\mathrm{w}}=539, \mathrm{p}<\right.$ $0.0001)$.

\section{Criminal history}

In relation to criminal history, $53 \%$ of the patients had been in prison at some stage in their life. This rate was higher in the Dual Users group (59\%) in comparison to the Powder Cocaine Users group (36.7\%) $\left(\chi^{2}=23.7, \mathrm{df}=1\right.$, $\mathrm{p}<0.0001)$ and was non-significantly lower in the Crack Cocaine Users $(49 \%)\left(\chi^{2}=2.6, \mathrm{df}=1, \mathrm{p}=0.1\right)$.

\section{Discussion}

In this study we describe socio-demographic characteristics and history of licit and illicit drugs of abuse among 699 Cocaine Users recruited from seven drug treatment hospitals located in the metropolitan region of Sao Paulo, Brazil. The analyses were conducted dividing the sample according to the preferred form of cocaine administration: 1) Powder Cocaine Users; 2) Crack Cocaine Users and 3) Dual users. The high frequency of concomitant use of crack with powder cocaine in our sample may be partly due to an increased availability - and a concomitant reduction in the price - of crack cocaine that occurred in the early 1990 's, which led to an explosion in consumption. Dunn et al. (1996) [7] and Ferri and Gossop (1999, 2001) [9,10] also reported increased crack use among patients who sought treatment in Sao Paulo clinics over this period. This had important social implications since crack cocaine users are more likely to report craving and impaired control of their drug use, tend to present higher levels of severity of dependence, higher involvement in prostitution, violence and crime $[17,18]$.

With respect to socio-demographic characteristics, our sample was essentially comprised of young, single, men with mainly primary education, corroborating previous published data about cocaine users attending treatment in Sao Paulo $[8,9,11]$. Comparing the different groups, Dual Users tended to differ from Powder Cocaine Users, regarding age, self-reported ethnicity, educational attainment and smoking status. Moreover, a high proportion of alcohol consumption was found in our sample with Dual Users reporting to drink more alcohol per week than Crack Cocaine Users. High prevalence for concurrent alcohol and cocaine misuse has been reported $[9,10]$. Epidemiological studies indicate that simultaneous abuse of powder cocaine and alcohol is widespread [19] and it is known that concurrent ingestion of cocaine and alcohol results in cocaethylene production $[20,21]$. Cocaethylene is a pharmacologically active homolog of cocaine with an increased metabolic half-life and may play a role in reinforcement effects of cocaine.

In addition, regarding the history of use of illicit drugs, Dual Users demonstrated a higher proportion of individu- als that had ever used cannabis and solvents in their life and cannabis in the last month. Polydrug abuse is a phenomenon reported by cocaine users in several other studies $[7,10,22]$ and represents an important concern to treatment and public health strategies. Polydrug users show complex life histories and are normally associated with poorer treatment outcomes than those using one drug only [22]. The latest data on hospital emergency visits estimates that more than half of the visits related to "drug misuse or abuse" involved more than one drug [23] and recent studies reported that simultaneous use of multiple drugs has been shown to contribute substantially to overdose mortality $[24,25]$. However, contrasting with the previously mentioned studies and with surveys in Europe where the consumption of opiates by cocaine users was important [26], the recent consumption of heroin was particularly low in our sample, reported by only 4 patients, less than $1 \%$ of the sample."

Eight-one per cent of our sample began using cocaine by snorting, agreeing with a previous study where $84 \%$ of the cocaine users in Sao Paulo [8] had chosen this route on the first occasion. Although the majority of the sample reported first use of cocaine by this route, $68 \%$ of those individuals went on to experience crack cocaine and $9 \%$ injected cocaine at some time of their life. However, when current Crack Cocaine Users were analyzed separately, ninety-two per cent of those reported first use of cocaine by smoking and, here, a smaller proportion of individuals went on experience powder cocaine $(43 \%)$ or injected cocaine (4\%). Interestingly most Dual Users (66\%) started using powder cocaine and then moved onto crack, supporting the suggestion that hydrochloride used intranasally may be a gateway drug or behaviour to using crack cocaine [17].

The presence of substance abuse and dependence are particularly associated with an increased risk of violent/homicidal behaviours [27]. Criminal activity was notably present in our sample. The Dual users groups were more likely to have been imprisoned in their life than the Powder Cocaine Users. Hatsukami and Fischman (1996) [17] reported crack cocaine to be linked with crime to a greater extent than cocaine hydrochloride, with many of these crimes being associated with the maintenance of drug consumption.

In summary, we found a high consumption of crack cocaine among the patients, corroborating with a historic change in the preference of cocaine use in Brazil in the past decade, reported by earlier studies. Furthermore we showed for the first time that interesting differences exist between Powdered, Crack and Dual Cocaine Users, a separate group, usually not considered in previous studies. The findings suggest that the Dual Users group differs from the 
mono users in several of the variables tested and appeared to be a distinct and more severe group regarding history of illicit drug abuse and rates of criminal history. They tended to have consumed significantly more cannabis and solvents. Moreover they also started consuming cocaine earlier in life and they were more likely to be actively involved in crime, showing higher percentage of individuals who have been arrested at least once in their life.

\section{Conclusion}

In conclusion, our results tended to agree with previous studies about cocaine and crack use in Brazil while offering some new information regarding the individuals who report use of both powder and crack cocaine. In the present study, this group presents differences to mono users, which suggests these individuals may be considered as a separate group. The main limitations of this study were that a small amount of information was available for certain key variables, e.g., for criminal history we did not record whether or not the conviction was for anti-social or violent behaviour, and that we had to rely on patient self report for other measures such as concomitant drug and alcohol use. However, the sample was large and from seven different centres, thus we might expect that the observations are clinically relevant, at least for the urban region of Sao Paulo.

\section{Competing interests}

The author(s) declare that they have no competing interests.

\section{Authors' contributions}

CG and GB analyzed the data, carried out statistical analysis and wrote the paper. RL was the psychiatrist coordinator of the sample collection. RL and HV participated in study design, and helped to revise drafts of the manuscript. All authors read and approved the final manuscript.

\section{Acknowledgements}

$\mathrm{GB}$ is an MRC Bioinformatics Training Fellow. This work was in part supported by FAPESP (Fundação para o Amparo à Pesquisa do Estado de São Paulo) and CAPEs (Coordenação de Aperfeiçoamento de Pessoal de Nível Superior).

\section{References}

I. Substance Abuse and mental Health Service Administration (SAMHSA): National Household Survey on Drug Abuse (NHSDA). 2003. Report

2. Haasen C, Prinzleve M, Zurhold H, Rehm J, Guttinger F, Fischer G, Jagsch R, Olsson B, Ekendahl M, Verster A, Camposeragna A, Pezous AM, Gossop M, Manning V, Cox G, Ryder N, Gerevich J, Bacskai E, Casas M, Matali JL, Krausz M: Cocaine use in Europe - a multicentre study. Methodology and prevalence estimates. Eur Addict Res 2004, I 0(4): I39-46.

3. Galduroz JCF, Noto AR, Nappo S, Carlini EA: I National Survey on psychotropic drugs use. Part A: Study of the 24 biggest cities of the Sao Paulo State. CEBRID (Centro Brasileiro de Informações sobre Drogas Psicotrópicas), UNIFESP - Federal University of São Paulo 2000.
4. Gossop M, Griffiths P, Powis B, Strang J: Cocaine: patterns of use, route of administration, and severity of dependence. $\mathrm{Br} J \mathrm{Psy}$ chiatry 1994, I 64(5):660-4.

5. Gossop M, Marsden J, Stewart D, Kidd T: The National Treatment Outcome Research Study (NTORS): 4-5 year followup results. Addiction 2003, 98(3):291-303.

6. Chen CY, Anthony JC: Epidemiological estimates of risk in the process of becoming dependent upon cocaine: cocaine hydrochloride powder versus crack cocaine. Psychopharmacology 2004, I 72:78-86

7. Dunn J, Laranjeira RR, Da Silveira DX, Formigoni ML, Ferri CP: Crack cocaine: an increase in use among patients attending clinics in Sao Paulo: 1990-1993. Subst Use Misuse 1996, 3 I:5 19-27.

8. Dunn J, Laranjeira RR: Transitions in the route of cocaine administration - characteristics, direction and associated variables. Addiction 1999, 94(6):813-24.

9. Ferri CP, Gossop M: Route of cocaine administration: patterns of use and problems among a Brazilian sample. Addict Behav | 999, 24:8|5-2|.

10. Ferri CP, Gossop M, Laranjeira RR: High dose cocaine use in Sao Paulo: a comparison of treatment and community samples. Subst Use Misuse 200I, 36:237-55.

II. Ferri CP, Dunn J, Gossop M, Laranjeira R: Factors associated with adverse reactions to cocaine among a sample of long-term, high-dose users in Sao Paulo, Brazil. Addict Behav 2004, 29(2):365-74

12. Ferreira Filho OF, Turchi MD, Laranjeira R, Castelo A: Epidemiological profile of Powder Cocaine Users on treatment in psychiatrics hospitals, Brazil. Rev Saude Publica 2003, 37:75I-9.

13. Dunn J, Ferri CP, Laranjeira R: Does multisite sampling improve patient heterogeneity in drug misuse research? Drug Alcohol Depend 2001, 63:79-85.

14. Dunn J, Laranjeira R: The development of a structured interview to evaluate cocaine use and risk behaviour. Rev Bras Psiquiatr 2000, 22(I): I I-6.

15. Turchi MD, Diaz RS, Martelli Turchi CM, Sabino EC, da Silva WP, Filho OF, Laranjeira RR, Busch MP, Castelo A: Genetic Diversity and HIV-I Incidence Estimation Among Powder Cocaine Users in Sao Paulo, Brazil. JAIDS Journal of Acquired Immune Deficiency Syndromes 2002, 30:527-532.

16. WHO: The ICD I 0 classification of mental and behavioural disorders. Diagnostic criteria for research 1993.

17. Hatsukami DK, Fischman MW: Crack cocaine and cocaine hydrochloride. Are the differences myth or reality? JAMA 1996, 276: I580-8.

18. Condon J, Smith N: Prevalence of drug use: key findings from the 2002/2003 British Crime Survey. Home Office 2003 [http:// www.crimereduction.gov.uk/drugsalcohol75.htm\#Prevalence].

19. Grant BF, Harford TC: Concurrent and simultaneous use of alcohol with cocaine: results of national survey. Drug Alcohol Depend 1990, 25(1):97-104.

20. McCance-Katz EF, Kosten TR, Jatlow P: Concurrent use of cocaine and alcohol is more potent and potentially more toxic than use of either alone - a multiple-dose study. Biol Psychiatry 1998, 44:250-9.

21. Farre M, De La Torre R, Llorente M, Lamas X, Balbina U, Segura J, Cami J: Alcohol and cocaine interactions in humans. J Pharmacol Exp Ther 1993, 266: I364-1373.

22. Prinzleve M, Haasen C, Zurhold H, Matali JL, Bruguera E, Gerevich J, Bacskai E, Ryder N, Butler S, Manning V, Gossop M, Pezous AM, Verster A, Camposeragna A, Andersson P, Olsson B, Primorac A, Fischer G, Guttinger F, Rehm J, Krausz M: Cocaine use in Europe - a multi-centre study: patterns of use in different groups. Eur Addict Res 2004, I 0(4): 147.

23. European Monitoring Centre for Drugs and Drug Addiction (EMCDDA): Annual report on the state of the drugs problem in the European Union. 2004.

24. U.S. Department of Health and Human Services, Substance Abuse and Mental Health Services Administration, Office of Applied Studies. Drug Abuse Warning Network 2003: Interim National Estimates of Drug-Related Emergency Department Visits. 2004.

25. Coffin PO, Galea S, Ahern J, Leon AC, Vlahov D, Tardiff K: Opiates, cocaine and alcohol combinations in accidental drug overdose deaths in New York City, 1990-98. Addiction 2003, 98(6):739-47. 
26. Seymour A, Oliver JS, Black M: Drug-related deaths among recently released prisoners in the Strathclyde Region of Scotland. Journal of Forensic Sciences 2000, 45:649-654.

27. Asnis GM, Kaplan ML, Hundorfean G, Saeed W: Violence and homicidal behaviours in psychiatric disorders. Psychiatr Clin North Am 1997, 20:405-25.

\section{Pre-publication history}

The pre-publication history for this paper can be accessed here:

http://www.biomedcentral.com/1471-2458/6/10/prepub

Publish with Bio Med Central and every scientist can read your work free of charge

"BioMed Central will be the most significant development for disseminating the results of biomedical research in our lifetime. " Sir Paul Nurse, Cancer Research UK

Your research papers will be:

- available free of charge to the entire biomedical community

- peer reviewed and published immediately upon acceptance

- cited in PubMed and archived on PubMed Central

- yours - you keep the copyright

Submit your manuscript here:

http://www.biomedcentral.com/info/publishing_adv.asp 